\title{
Health Care Utilization among Chronic Obstructive Pulmonary Disease Patients and the Effect of Pulmonary Rehabilitation
}

\author{
Mohamed S. Al Moamary \\ College of Medicine, King Saud bin Abdulaziz University for Health Sciences, and Department of Medicine, \\ King Abdulaziz Medical City, Riyadh, Saudi Arabia
}

\section{Key Words}

Chronic obstructive pulmonary disease $\cdot$ Pulmonary rehabilitation $\cdot$ Cost of illness

\begin{abstract}
Objective: The present study aimed to analyze the utilization of health care resources among patients with chronic obstructive pulmonary disease (COPD) and to evaluate the effect of adherence to a pulmonary rehabilitation (PR) program on the utilization of these resources. Subjects and Methods: A retrospective review of medical charts of a group of patients with COPD who were enrolled in a standard outpatient PR program at a tertiary care teaching hospital was conducted. Eligible patients were above the age of 18 years with a history of dyspnea, chronic cough and/or exposure to a disease risk factor with a postbronchodilator $\mathrm{FEV}_{1} / \mathrm{FVC}$ ratio <0.7. Results: Fifty patients were referred to the PR program. The average number of emergency department visits was $1.4 \pm 1.6$ days, the length of stay in the hospital was $1.7 \pm 3.8$ days, the pulmonary clinic scheduled visits were $3.9 \pm 2.2$, the use of combined inhalers was $9.0 \pm$ 3.9 canisters, the use of short-acting bronchodilator was 9.0 \pm 5.6 canisters, the cumulative prednisone doses were 427.5 $\pm 463 \mathrm{mg}$, and the use of antibiotic courses was $3.1 \pm 2.9$. Of the referred patients, 27 (54\%) were adherent and 23
\end{abstract}

(46\%) were not. Except for the use of combined inhalers, all parameters were significantly reduced in the adherent group. In contrast, the nonadherent group had increases in use of prednisone and antibiotics $(p<0.05)$. Conclusion: There was a reduction in the utilization of health care resources among adherent patients with COPD who completed a PR program as reflected in selected pharmacological and nonpharmacological parameters.

Copyright $\odot 2010$ S. Karger AG, Base

\section{Introduction}

Chronic obstructive pulmonary disease (COPD) is a systemic disease that leads to substantial economic and social burdens due to its related morbidity and premature mortality. The death rates from COPD doubled over the past decades and led to growing awareness of the impact on the health care systems worldwide [1-3]. The prevalence of this disease varies from 6 to $32 \%$ and is higher among the older age group, smokers and men [4-6]. Nevertheless, this problem is underrecognized in the Middle East as manifested by the paucity of economic data and the lack of adequate awareness among health care workers. A report from a university hospital about hospitalizations in Saudi Arabia published in 2006 demonstrated

\section{KARGER}

Fax +4161306 1234

E-Mail karger@karger.ch

www.karger.com
(C) 2010 S. Karger AG, Basel

1011-7571/10/0195-0373\$26.00/0

Accessible online at:

www.karger.com/mpp
Dr. Mohamed S. Al Moamary

College of Medicine

King Saud bin Abdulaziz University for Health Sciences

P.O. Box 84252, Riyadh 11671 (Saudi Arabia)

E-Mail almoamary@yahoo.com 
that COPD was the second most prevalent diagnosis among hospitalized patients with respiratory disorders and constituted $17 \%$ of the hospitalizations [7].

Studies have shown that participation in pulmonary rehabilitation (PR) has reduced the utilization of health care resources and improved the quality of life of patients with COPD [8-10]. In Saudi Arabia, PR is in its early stages and was first introduced in 2001. It was found to be feasible and led to marked improvement in exercise performance and overall physical fitness [11]. Therefore, the objective of this study was to determine the utilization of health care resources among patients with COPD and to evaluate the effect of the PR program on the utilization of these resources.

\section{Subjects and Methods}

This is a retrospective study in a group of patients with COPD who were referred to the Pulmonary Rehabilitation Center at King Abdulaziz Medical City, a tertiary care teaching hospital in Riyadh, Saudi Arabia. It covered the period from 1st July 2004 to 15th January 2008. The PR program was established in 2001 and is the only available program that provides PR in the country. Medical charts of patients with a diagnosis of COPD as defined by criteria of the Global Initiative for COPD (GOLD) were included in this study. Medical charts were reviewed if the patient was above the age of 18 years, had a history of dyspnea, had chronic cough and/or exposure to a disease risk factor with a postbronchodilator $\mathrm{FEV}_{1} / \mathrm{FVC}$ (forced expiratory volume in $1 \mathrm{~s} /$ forced vital capacity) ratio $<0.7$. The COPD severity index was adopted from the GOLD [4]. A patient's medical chart had to be available for 12 months prior to enrolment in the PR program and 12 months after the completion date of the PR or last visit. Acceptance in the program required a prior review and optimization of COPD treatment in the pulmonary clinic by ensuring that the patient received appropriate therapy for the stage of the disease severity [4].

Adherence to the PR program required the patients to complete the PR protocol by attending a 1-hour session, 2-3 times per week over 8-12 weeks for a total of 18-24 sessions in an outpatient setting. The patients were discharged from the PR program at 8 weeks provided that they had completed 18 sessions or that they would complete 18 sessions within 8-12 weeks. The program consisted of exercises combining track or treadmill walking, upright cycling, stair stepping and arm ergometer. Direct small group education sessions were conducted by the PR physiotherapist. Both the exercise and education programs were carried out as previously described [11]. The program provided exercise therapy consisting of combination treadmill or track walking, upright cycling, stair stepping and arm ergometer. The intensity of the exercises was individualized based on the patient's tolerance, physiological parameters and PR physiotherapist judgment. Aerobic exercises comprised upper extremity, lower extremity, flexibility and strength. The educational component included modules covering obstructive and restrictive lung diseases, breath retraining, pulmonary hygiene, dietary modification, risk factor modification, pulmonary medications and equipment, stress management/relaxation, smoking cessation advice, exercise benefits, musculoskeletal injury prevention and overall pulmonary disease intervention.

This study received the appropriate institutional approval for retrospective trials. The patient data were coded at inclusion in the database to preserve confidentiality.

The basic demographic and physiological data were retrieved from the medical record. The following outcome parameters were collected from the medical chart: number of hospital admissions, length of stay (LOS) during admissions to the hospital, as well as visits to the emergency department (ED) and to pulmonary outpatient clinics (OPC). Pharmacological parameters that included combined inhalers (long-acting bronchodilator and corticosteroids), short-acting bronchodilator inhalers, cumulative prednisone dose and antibiotic courses were collected. Combined inhalers referred to Symbicort turbohaler (budesonide and formeterol) and Seretide (fluticasone and salmeterol) in the form of discus or evohaler. Tiotropium inhalers were not included in this study because they entered the hospital formulary in 2006 and were not available throughout the study period. The FEV 1 was performed by a pulmonary function system manufactured by Jaeger Master Lab, Germany. It was calculated from the best of at least 3 trials of postbronchodilator $\mathrm{FEV}_{1}$ measurements as recommended by the American Thoracic Society [12]. The 6-minute walk test was performed according to the guidelines of the American Thoracic Society by obtaining the better of 2 tests taken a few days apart [13].

For statistical analysis, pre- and postcomparisons were made between the adherent and nonadherent groups. Continuous variables were summarized by calculating the mean and the standard deviation, whereas categorical variables were summarized by determining the number and percentage. The association between different categorical variables was assessed with the $\chi^{2}$ test, whereas the paired and unpaired $t$ test was used for the association with the continuous variables. A $\mathrm{p}$ value $<0.05$ was considered statistically significant. Data management and analyses were carried out using the SPSS program, version 16.

\section{Results}

In this retrospective study, the medical charts of 62 patients with a diagnosis of COPD were referred to the PR program. Twelve patients were not eligible either due to refusal to be enrolled in the PR program (8 patients; $66.7 \%$ ) or to inadequate medical chart (4 patients; 33.3\%). The characteristics of those 12 patients were as follows: age $63.4 \pm 13.5$ years, 5 men (41.7\%), 7 women (58.3\%) and $\mathrm{FEV}_{1} 53.2 \pm 17.3$ of predicted. The demographic characteristics of the 50 patients $(80.6 \%)$ who agreed to enrol in the program are summarized in table 1 . There were 27 males (54\%) and 23 females (46\%) with a mean age of $66.0 \pm 11.9$ years. Of the study population, $27 \mathrm{pa}-$ tients $(54 \%)$ were adherent to the PR program and 23 (46\%) were not. The 27 patients adherent to the PR at- 
Table 1. Baseline demographic data of the 50 consecutive patients with COPD enrolled in the PR program

\begin{tabular}{|c|c|c|c|c|}
\hline & $\begin{array}{l}\text { Adherent } \\
(\mathrm{n}=27)\end{array}$ & $\begin{array}{l}\text { Nonadherent } \\
(\mathrm{n}=23)\end{array}$ & $\begin{array}{l}\text { All patients } \\
(\mathrm{n}=50)\end{array}$ & $\begin{array}{l}\mathrm{p} \\
\text { value }\end{array}$ \\
\hline Age, years & $65.2 \pm 10.6$ & $66.9 \pm 13.4$ & $66 \pm 11.9$ & 0.61 \\
\hline Gender & & & & 0.81 \\
\hline Male & $15(55.6)$ & $12(52.2)$ & $27(54)$ & \\
\hline Female & $12(44.4)$ & $11(47.8)$ & $23(46)$ & \\
\hline Body mass index & $28 \pm 7.6$ & $26 \pm 7.2$ & $27.1 \pm 7.4$ & 0.33 \\
\hline $\mathrm{FEV}_{1}^{\mathrm{a}}$ & $51.4 \pm 21.7$ & $47.2 \pm 18.4$ & $49.4 \pm 20.2$ & 0.47 \\
\hline $\mathrm{FVC}^{\mathrm{a}}$ & $65.9 \pm 18.8$ & $59.4 \pm 18.8$ & $62.9 \pm 18.9$ & 0.23 \\
\hline $\mathrm{FEV}_{1} / \mathrm{FVC}$ & $61.4 \pm 15.9$ & $63.7 \pm 18.7$ & $62.4 \pm 17.1$ & 0.64 \\
\hline Total lung capacity ${ }^{a}$ & $85.9 \pm 13.9$ & $85.1 \pm 14.6$ & $85.6 \pm 14.1$ & 0.85 \\
\hline Diffusion capacity ${ }^{\mathrm{a}}$ & $51.7 \pm 23.4$ & $50.2 \pm 21.8$ & $51.0 \pm 22.5$ & 0.81 \\
\hline $\mathrm{PaO}_{2}, \mathrm{~mm} \mathrm{Hg}$ & $46.4 \pm 11.9$ & $47.4 \pm 9.3$ & $46.9 \pm 10.7$ & 0.76 \\
\hline $\mathrm{PaCO}_{2}, \mathrm{~mm} \mathrm{Hg}$ & $59.7 \pm 12.4$ & $64.1 \pm 11.1$ & $61.7 \pm 11.9$ & 0.19 \\
\hline Right ventricular dilatation & & & & 0.46 \\
\hline Absent & $18(66.7)$ & $13(56.5)$ & $31(62)$ & \\
\hline Present & $9(33.3)$ & $10(43.5)$ & $19(38)$ & \\
\hline COPD severity GOLD stage & & & & 0.38 \\
\hline Mild & $4(14.8)$ & $1(4.3)$ & $5(10)$ & \\
\hline Moderate & $9(33.3)$ & $5(21.7)$ & $14(28)$ & \\
\hline Severe & $9(33.3)$ & $12(52.2)$ & $21(42)$ & \\
\hline Very severe & $5(18.5)$ & $5(21.7)$ & $10(20)$ & \\
\hline Six-minute walk test, $\mathrm{m}$ & $218 \pm 113.4$ & $167.4 \pm 117.9$ & $194.7 \pm 117.1$ & 0.13 \\
\hline
\end{tabular}

Figures are means \pm SD or numbers of cases with percentages in parentheses. ${ }^{\text {a }}$ Percent of predicted.

tended $19.4 \pm 1.9$ sessions with a range of $18-24$ sessions. The results of the 6-minute walk test improved in the adherent group from an average of 218 to $339 \mathrm{~m}$.

There were no significant differences in the demographic characteristics, clinical status, pulmonary function, arterial blood gases, presence of right ventricular dilatation, COPD severity or performance on the 6-minute walk test between the adherent and nonadherent groups (table 1). The reasons for nonadherence for the 23 patients were interruption of PR by admission to the hospital in 7 patients $(30.4 \%), 3(13.0 \%)$ had difficulties with transportation, $2(8.6 \%)$ could not tolerate the program and $11(47.8 \%)$ did not specify a reason.

The utilization of selected health care parameters over the 12-month period prior to enrolment in the PR program is shown in table 2 . The 10 patients admitted to the hospital had an average LOS of 9.2 days per patient. It also shows that patients with severe disease tend to have more ED visits, as well as increased LOS, cumulative dose of prednisone and antibiotic courses. In the adherent group, patients with severe disease dropped their ED visits from 1.3 to 0.7 , LOS from 1.9 to 1.8 and OPC visits from 3.6 to 2.4 (table 2).

Health Care Utilization among COPD Patients
Except for the number of combined inhalers, table 3 illustrates that all other outcome measures in the adherent group showed significant improvement after the completion of the PR for patients who were adherent. In the nonadherent group, there was a trend toward increased utilization of health care resources. This reached statistical significance in the cumulative dose of prednisone and antibiotic courses. Further comparison between the adherent and nonadherent groups showed significant variation in the mean of the difference between pre- and post-PR (table 3).

\section{Discussion}

There was a reduction in the utilization of health care resources among adherent patients with COPD after the completion of a PR program as reflected in selected pharmacological and nonpharmacological parameters. A novel aspect of the present study is that, to the author's knowledge, it is the first paper of its kind from Saudi Arabia and probably from the Middle East region that addresses health care utilization among patients with

Med Princ Pract 2010;19:373-378 
Table 2. Health care utilization for 50 COPD patients 12 months prior to their enrollment in PR stratified based on disease severity

\begin{tabular}{|c|c|c|c|c|c|c|c|}
\hline & \multirow[t]{2}{*}{ Patients } & \multicolumn{2}{|c|}{ Emergency department visits } & \multicolumn{2}{|c|}{ Length of stay, days } & \multicolumn{2}{|c|}{ Outpatient department visits } \\
\hline & & pre-PR & post-PR & pre-PR & post-PR & pre-PR & post-PR \\
\hline \multicolumn{8}{|l|}{ Adherent } \\
\hline Mild to moderate & 13 & $1.6 \pm 1.3$ & $0.9 \pm 0.8$ & $1.8 \pm 2.9$ & $0.1 \pm 0.3$ & $5.4 \pm 1.1$ & $2.8 \pm 0.8$ \\
\hline Severe and very severe & 14 & $2.3 \pm 2.2$ & $0.7 \pm 0.8$ & $1.9 \pm 4.5$ & $2.2 \pm 1.8$ & $5.6 \pm 2.3$ & $2.4 \pm 1.0$ \\
\hline \multicolumn{8}{|l|}{ Nonadherent } \\
\hline Mild to moderate & 6 & $1.2 \pm 1.3$ & $1.2 \pm 1.3$ & $0.0 \pm 0.0$ & $0.0 \pm 0.0$ & $2.2 \pm 1.2$ & $2.5 \pm 1.4$ \\
\hline Severe and very severe & 17 & $0.5 \pm 0.7$ & $0.8 \pm 1.0$ & $0.4 \pm 0.8$ & $2.6 \pm 4.5$ & $2.2 \pm 1.3$ & $2.5 \pm 1.8$ \\
\hline
\end{tabular}

COPD. Though data related to COPD epidemiology are scanty in the Middle East, the prevalence of the diseases is expected to increase due to higher prevalence of smoking and rapid modernization and industrialization in the past few decades [14-17].

The medical charts of a group of 50 patients with COPD with an average $\mathrm{FEV}_{1}$ of $49 \%$ were included in this study. Over a period of 12 months, for all patients, the average ED visits were 1.4, LOS was 1.5 and the number of OPC visits 3.9. These results are consistent with those of the California Pulmonary Rehabilitation Collaborative Group, where the mean hospital stay of 521 patients was 2.4 days, the number of urgent care visits was 0.4 and that of physician visits 4.4 [8]. On the other hand, the result by Griffiths et al. [18] showed that their patients had an average LOS in the hospital of 10.4 days and 7.3 OPC visits. The data in the present study and in that by Griffiths et al. were collected by chart review, while the California group collected their data by self-reporting. The present data are more consistent with the California group as there are similarities in the restriction on inpatient admissions due to unavailability of beds and the emphasis on initiation of treatment in the ED with continuation in the OPC. This improvement was also observed in the 6-minute walk test by an average increment of $121 \mathrm{~m}$ in the adherent group. A clinically significant improvement in the 6-minute walk test is considered to be $>54 \mathrm{~m}$ [19-23].

The GOLD has emphasized the spirometric classification of COPD severity, since it has important clinical implications on management, selection of treatment modality and prognosis. In the current study, patients with severe disease utilized health care system resources more than those with mild to moderate disease. Moreover, COPD severity was also found to be directly related to the associated morbidity and mortality and strongly correlated with total treatment cost [6]. This was supported by a study from Sweden showing that the costs of severe disease were 3 times more than those of moderate disease and 10 times more than those of mild disease [24].

After the patients had completed the PR program, the number of short-acting bronchodilator inhalers was reduced by $51 \%$ in the adherent group, while the number of combined inhalers remained the same. This could indicate that better compliance with combined inhaler use led to less utilization of short-acting inhalers. The use of prednisone and antibiotics was also significantly reduced in the adherent group by 35 and 53\%, respectively. In the nonadherent group, there was a significant increase in the use of prednisone and antibiotics by 38 and $31 \%$, respectively. This indeed reflects better adherence to the prescribed program and a less acute exacerbation as demonstrated by a $60 \%$ reduction in ED visits for those who completed the PR program. Foglio et al. [25] observed a significant decrease in acute exacerbations of COPD from 3.2 to 1.2 per year upon completion of a PR program. The described findings related to medications in the present study are unique as there are scant data on the pharmacological utilization in COPD [3].

COPD prevalence is increasing and illness duration is life-long. Therefore, the cost on the health system is both direct and indirect, mostly due to hospitalization [26, 27]. Strassels et al. [28] reported that hospitalization and emergency visits contributed more than two thirds of the cost, while the remaining cost was related to OPC visits and medications. It is interesting that $10 \%$ of the patients consumed $73 \%$ of the allocated resources. Considering the economic impact of the disease and the financial strains, health care providers should efficiently utilize health care resources [29]. Apparently, PR had been shown to be cost-effective and improve the quality of life 


\begin{tabular}{|c|c|c|c|c|c|c|c|}
\hline \multicolumn{2}{|c|}{ Combined inhaler use } & \multicolumn{2}{|c|}{ Short-acting bronchodilator use } & \multicolumn{2}{|c|}{ Cumulative prednisone dose } & \multicolumn{2}{|c|}{ Antibiotics use } \\
\hline pre-PR & post-PR & pre-PR & post-PR & pre-PR & post-PR & pre-PR & post-PR \\
\hline $8.6 \pm 3.7$ & $9.5 \pm 2.1$ & $8.5 \pm 2.5$ & $4.5 \pm 2.3$ & $307 \pm 427$ & $145 \pm 260$ & $2.7 \pm 1.1$ & $1.5 \pm 0.7$ \\
\hline $9.3 \pm 4.0$ & $8.9 \pm 3.1$ & $9.8 \pm 6.4$ & $5.3 \pm 1.9$ & $502 \pm 432$ & $365 \pm 401$ & $3.3 \pm 3.2$ & $1.6 \pm 1.3$ \\
\hline $7.8 \pm 3.1$ & $8.1 \pm 3.1$ & $6.3 \pm 5.7$ & $7.3 \pm 5.9$ & $426 \pm 527$ & $513 \pm 563$ & $2.7 \pm 3.8$ & $3.0 \pm 3.1$ \\
\hline $9.1 \pm 4.1$ & $8.5 \pm 3.9$ & $0.8 \pm 2.4$ & $0.6 \pm 1.7$ & $472 \pm 451$ & $666 \pm 503$ & $3.1 \pm 3.0$ & $4.1 \pm 3.0$ \\
\hline
\end{tabular}

Table 3. Health care utilization per COPD patient classified based on adherence to PR

\begin{tabular}{|c|c|c|c|c|c|c|c|c|c|}
\hline Parameter & \multicolumn{4}{|c|}{ Adherent patients $(\mathrm{n}=27)$} & \multicolumn{4}{|c|}{ Nonadherent patients $(n=23)$} & p value ${ }^{a}$ \\
\hline Length of stay, days & $2.2 \pm 4.1$ & $0.6 \pm 1.7$ & $-1.6 \pm 3.5$ & 0.02 & $1.0 \pm 3.5$ & $1.9 \pm 4.1$ & $0.9 \pm 3.7$ & 0.26 & 0.0172 \\
\hline Outpatient clinic visits & $5.3 \pm 1.8$ & $2.6 \pm 0.9$ & $-2.7 \pm 1.3$ & $<0.0001$ & $2.2 \pm 1.3$ & $2.5 \pm 1.7$ & $0.3 \pm 1.3$ & 0.27 & $<0.0001$ \\
\hline Combined inhalers & $9.3 \pm 3.8$ & $9.2 \pm 2.6$ & $-0.1 \pm 2.2$ & 0.79 & $8.7 \pm 4.1$ & $8.3 \pm 3.7$ & $-0.4 \pm 2.3$ & 0.37 & 0.6065 \\
\hline Antibiotics courses & $3.2 \pm 2.7$ & $1.5 \pm 1.0$ & $-1.7 \pm 2.0$ & $<0.0001$ & $2.9 \pm 3.1$ & $3.8 \pm 3.0$ & $0.9 \pm 1.4$ & 0.01 & $<0.0001$ \\
\hline
\end{tabular}

a Significance of the comparison of the mean difference of both adherent and nonadherent groups before and after PR.

of affected patients $[25,28,29]$. Though PR is not yet practiced as a standard modality for COPD management nationwide, the impact of COPD in Saudi Arabia, a country with an emerging economy, is expected not to be different from developed countries.

This observational study had inadequate adjustment of confounding variables that may influence adherence to the PR program. It was also conducted in a single center with a small sample size, as the Pulmonary Rehabilitation Center is the first and only available place that provides this service in the country. The other limitation was the lack of measurement of quality of life due to unavailability of a validated Arabic instrument until late 2006.

\section{Conclusion}

Based on selected pharmacological and nonpharmacological parameters, there was a reduction in the utilization of health care resources for patients with COPD after the completion of a PR program as reflected in selected pharmacological and nonpharmacological parameters. This further supports the evidence that patients with COPD should be encouraged to attend and complete PR as part of their standard management.

\section{Acknowledgment}

The author would like to thank Dr. Hani Tamim from the Evidence-Based Medicine Unit in the College of Medicine, King Saud bin Abdulaziz University for Health Sciences, and Einas Khalifa and Naifa Al Aida from the Pulmonary Rehabilitation Center for their contribution in providing patient data. 


\section{References}

1 Jemal A, Ward E, Hao Y, Thun M: Trends in the leading causes of death in the United States, 1970-2002. JAMA 2005;294:12551259.

$>2$ Mannino DM, Homa DM, Akinbami LJ, Ford ES, Redd SC: Chronic obstructive pulmonary disease surveillance - United States, 1971-2000. MMWR Morb Mortal Wkly Rep 2002;51:1-16.

$>3$ Sullivan S, Ramsey S, Lee T: The economic burden of COPD. Chest 2000;117:S5-S9.

4 Global Initiative for Chronic Obstructive Lung Disease: Global Strategies for Diagnosis, Management, and Prevention of COPD. Executive Summary. 2006. http://www.goldcopd.org (accessed August 2, 2007).

$\checkmark 5$ Al Moamary MS: Pulmonary rehabilitation: the standard practice ... not yet standard. Ann Thorac Med 2006;1:65-66.

$\checkmark 6$ Hilleman D, Dewan N, Malesker M, Friedman M: Pharmacoeconomic evaluation of COPD. Chest 2000;118:1278-1285.

7 Alamoudi OS: Prevalence of respiratory diseases in hospitalized patients in Saudi Arabia: a 5-year study 1996-2000. Ann Thorac Med 2006;1:76-80.

$>8$ California Pulmonary Rehabilitation Collaborative Group: Effects of pulmonary rehabilitation on dyspnea, quality of life and healthcare costs in California. J Cardiopulm Rehabil 2004;24:52-62.

$>9$ Wijkstra PJ, Ten Vergert EM, van der Mark TW, Postma DS, Van Altena R, Kraan J, Koëter G: Relation of lung function, maximal inspiratory pressure, dyspnoea, and quality of life with exercise capacity in patients with chronic obstructive pulmonary disease. Thorax 1994;49:468-472.

10 Golmohammadi K, Jacobs P, Sin DD: Economic evaluation of a community-based pulmonary rehabilitation program for chronic obstructive pulmonary disease. Lung 2004;182:187-196.
11 Al Moamary MS: Experience with pulmonary rehabilitation in a tertiary care center in Saudi Arabia. Saudi Med J 2008;29:477-482.

12 American Thoracic Society: Standardization of spirometry. Am J Respir Crit Care Med 1995;152:1107-1136.

13 Brooks DS, Solway S, Gibbons WJ: ATS statement on six-minute walk test. Am J Respir Crit Care Med 2003;167:1287.

14 Jha P, Ranson K, Nguyen N, Yach D: Estimates of global and regional smoking prevalence in 1995, by age and sex. Am J Public Health 2002;92:1002-1006.

15 Døssing M, Khan J, Al-Rabiah F: Risk factors for chronic obstructive lung disease in Saudi Arabia. Respir Med 1994;88:519-522.

16 Ali B, Ballal S, Albar A, Ahmed H: Post-shift changes in pulmonary function in a cement factory in eastern Saudi Arabia. Occup Med 1998;48:519-522.

17 Siddiqui S, Ogbeide DO, Al Khalifa I: Smoking in a Saudi community: prevalance, influencing factors, and risk perception. Fam Med 2001;33:367-370.

18 Griffiths T, Burr M, Campbell I, Lewis-Jenkins V, Mullins J, Shiels K, Turner-Lawlor P, Payne N, Newcombe R, Lonescu A: Results at 1 year of outpatient multidisciplinary pulmonary rehabilitation: a randomised controlled trial. Lancet 2000;355:362-368.

19 Goldstein RS, Gort EH, Avendano M, Stubbing D, Guyatt G: Randomised control trial of pulmonary rehabilitation. Lancet 1994; 344:1394-1397.

20 Bendstrup KEJ, Ingemann-Jensen S, Holm S, Bengtsson B: Out-patient habilitation improves activity of living, quality of life and exercise tolerance in chronic obstructive pulmonary disease. Eur Respir J 1997;10: 2801-2806.
21 Wedzicha JA, Bestall JC, Garrod R, Garnham R, Paul E, Jones P: Randomized controlled trial of pulmonary rehabilitation in severe chronic obstructive pulmonary disease patients, stratified with MRC dyspnoea scale. Eur Respir J 1998;12:363-369.

22 Hui K, Hewitt A: A Simple pulmonary rehabilitation program improves health outcomes and reduces hospital utilization in patients with COPD. Chest 2003;124:94-97.

23 Redelmere DA, Bayoumi AM, Goldstein RS, Guyatt G: Interpreting small differences in functional status: the six-minute walk test in chronic lung disease patients. Am J Respir Crit Care Med 1997;155:1278-1282.

-24 Jansson S, Andersson F, Borg S, Ericsson Å, Jönsson E, Lundba B: Costs of COPD in Sweden according to disease severity. Chest 2002;122:1994-2002.

-25 Foglio K, Bianchi L, Bruletti G, Battista L, Pagani M, Ambrosino N: Long-term effectiveness of pulmonary rehabilitation in patients with chronic airway obstruction. Eur Respir J 1999;13:125-132.

26 National Heart, Lung and Blood Institute: Morbidity and mortality: 2004 chart book on cardiovascular, lung and blood diseases. http://www.nhlbi.nih.gov/resources/ docs/04_chtbk.pdf (accessed September 13, 2004).

27 Division of Epidemiology, National Heart, Lung and Blood Institute. 1996.http://www. nhlbi.nih.gov.

28 Strassels S, Smith D, Sullivan S, Mahajan P. The costs of treating COPD in the United States. Chest 2001;119:344-352.

29 Pauwels RA, Buist AS, Calverley PM, Jenkins C, Hurd S: Global strategy for the diagnosis, management, and prevention of chronic obstructive pulmonary disease: NHLBI/WHO Global Initiative for Chronic Obstructive Lung Disease (GOLD) Workshop summary. Am J Respir Crit Care Med 2001;163:12561276. 